\title{
Design AND CONSTRUCTION OF A MODUlar COST-EFFECTIVE CNC MACHINE
}

\author{
Arbnor Pajaziti, Tafil Asllani \& Afrim Gjelaj
}
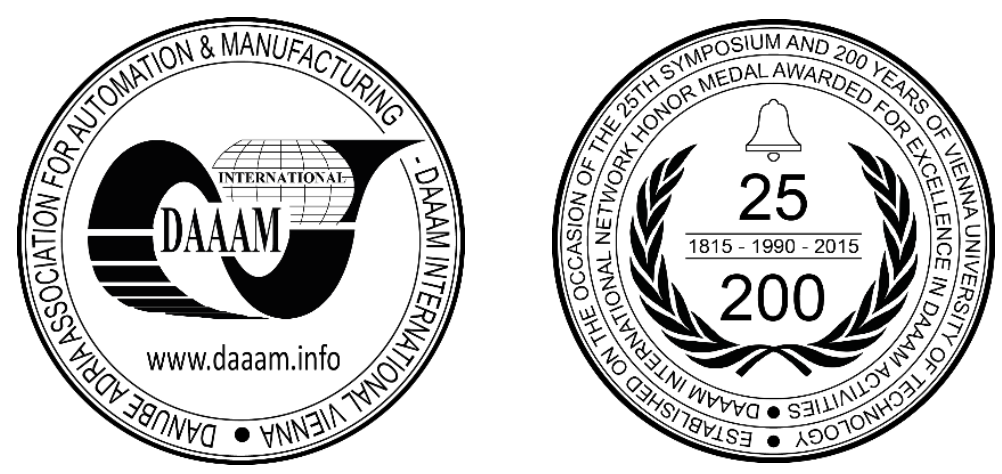

This Publication has to be referred as: Pajaziti, A[rbnor]; Asllani, T[afil] \& Gjelaj, A[frim] (2017). Design And Construction of a Modular Cost-Effective CNC Machine, Proceedings of the 28th DAAAM International Symposium, pp.0229-0236, B. Katalinic (Ed.), Published by DAAAM International, ISBN 978-3-902734-11-2, ISSN 1726-9679, Vienna, Austria

DOI: $10.2507 / 28$ th.daaam.proceedings.031

\begin{abstract}
Main goal of the paper is design and construction of a prototype CNC machine which has the function of drawing, cutting, milling and drilling on a working table. We tried to describe in details all the steps we have undertaken from the beginning to the end of the work, with regards to design of mechanical parts, electrical parts and software developments. Our strength relied on the design and construction of functional prototype quickly, cost-effectively and with high precision.

To meet the above-mentioned criteria, in our study we have chosen several tasks to compile and execute the programs from the computer with the help of Lazy CAM Mach3 software, and then transfer of data on CNC machine, which performs the sequences by moving the $\mathrm{z}$ axis and draw or cut on $\mathrm{x}, \mathrm{y}$ axes. The required critical components such as motors and linear guides have been carefully compared and selected. Personal computer has been used to design the parts and also is used to compile programs by either manual typing of G-Code.

The machine described in the paper will help to solve high precision machine tool system problem and serve those who demand to fabricate the CNC machines with low costs.
\end{abstract}

Keywords: CNC Machine design; low cost automation; CNC software; CNC graphical user interface; G-code

\section{Introduction}

CNC machines nowadays are widely used in manufacturing industry and are able to be controlled by programming language to carry out a wider variety of tasks with greater accuracy. The main issue during the design and construction of a CNC machine is how to eliminate unpredicted vibrations in mobile supporters $\mathrm{x}, \mathrm{y}$ and $\mathrm{z}$ axis.

Computer Numeric Control (CNC) - brought a new opportunity to control the machine through the introduction of an integrated computer to the process control. To control the functions of the machine such as the movement of the tip of the pen, the movement of the cutting instrument, the movement of the work piece, changes in the cutting tool, etc., CNC takes instructions from the program in the form of program-sequences and translates from the control of machine to output analogue signals through postprocessors.

For modelling the movement characteristics in 1995, D. Spath [1], and in 1999, H. Weule [2] has studied the kinematics and trybo-system of circular spheres screw and has provided its specifics and priorities on growth speed of 
the moving table. Y. Zhou et al. [3], in 2011, proposed a detailed modelling of the support mechanism of, taking into account hardness and masses of all the mechanical elements of screw system with circulation spheres, to be used for analysis of vibrations by using the finite element method. D. Prevost et al., in 2011 [4], from simulation of contour errors, have proposed modelling of the movement of the food based on five axial milling centre for high-speed work, and have considered the factors that influence mostly in the dynamic behaviour of axes, inertia, friction and open contour compensation control [4].

To control the movement of feed rate, all elements of the feed rate system should be taken into consideration. D. Prevost [4] has proposed the allocation of process control in three levels: digital level - real-time interpretation program sequences of CL-file data to generate commands of axes.

At this level, the numerical control unit calculates position and speed kinematics limits based on each axle. The second level, the support mechanism - includes files and elements that perform axial commands, after the conversion of analogue to digital data. The third level - the kinematic level, consisting of mechanical structure of CNC machine, such as the kinematic chain, creates relative movement between the instrument and the piece.

Some authors have proposed modelling at each level (Altintas, 2005) [5], while others have preferred a specific work piece-modelling. The first model of the trajectory of movement is proposed by Lavernhe, 2008 [6]. Altintas et al. in 2000 [7], have proposed an adaptive sliding controller type (SMC-Siding Mode Controller) for the control of the movement of support mechanism and the contour movement during milling. The controller is implemented in the screw system with circulation areas and has shown more sophisticated and convenient method to control speed, better than the classic cascade controllers.

An integrated control, kinematics and dynamics of the circulation spheres screw servo-system have been given by Min-Seok Kim [8] in 2006. He has designed in details the requirements of the stability of servo-mechanism, geometric errors, stresses of the structure etc.

Implementation of artificial intelligence techniques to control support mechanism movement has given good results and is mainly observed in combination with the PID regulator. Lacerda et al. [9] in 1999 in order to minimize the contour errors has proposed a PID + Fuzzy Hybrid Controller (FHC) that manages to reduce contour errors at the 70:1 ratio.

Jin-Sung Kim et al. in 2008 [10], did the adjustment of the PID coefficients with genetic algorithm. In 2009 Isayad Naimuddin et al. [11], they have applied the Fuzzy Logic Controller (FLC) to the closed circuit inductive motor. In March 2011 F. Cus et al. [12], have published an article which represents an intelligent controller to control the milling force by combination of open and closed contour. The force is corrected from the external perturbations through closed loop, while through open loop with neural network the inverse dynamics of the production process is simplified. Meanwhile, various tests have been carried out with variants of implementation techniques. Gayathri J. et al. [13], 2011 have demonstrated the effect of different forms of membership functions to control alternating motor current, etc.

Therefore, in order to preserve the principle of simplicity of modelling the system and escape from the use of mathematics, the set of important elements that cause the destruction of stability have to be considered:

- Control of the inertia growth of the masses movement;

- Discontinuities that are raised during the goal of setting points;

- Non-linearity arising from random errors;

- Changes of the resisting forces of the cutting process.

Determining the shape of the system modelling for movement of drawing table will be explained in more details in Section III. Based on the model, the virtual simulation and the real CNC machine with the help of SOLIDWORKS has been designed and constructed.

\section{Research goals}

\subsection{Precision increase}

Recently there has been a particular interest in terms of increasing the accuracy of the metal-processing machines and their application in various fields. This has led to increased interest in processing centres of CNC machines that offer high speed machining, optimal efficiency, high precision and whose aim is to reduce the cost. High machining speed means the systems with fast support mechanism and with high cutting speed.

The z-axis speed ranges from $600 \mathrm{~m} / \mathrm{min}$ and over 18,000 $\mathrm{m} / \mathrm{min}$ for ultra fast. High processing speed and great accuracy is required to increase the productivity of $\mathrm{CNC}$ machines, to shorten working time and preparatory steps, to fabricate complicated work pieces, etc.

\subsection{Questions and hypothesis}

The main question would be, whether the goal would be reached only by following the correct programming on CNC machine, or there is a need to pay particular attention on implementation stages of design and production of the prototype by applying the FLC of the closed loop of inductive motor.

The hypothesis would be performance and additional information about how the machines are designed and constructed that would be used as expected results. 
- What is the purpose of creating such a device?

The study is focused on the design, construction and testing of CNC machine which today has been implemented mostly in industry of producing the electrical items.

- What are the expected results?

Drawings are designed to present various contours through the Mach3 program and are ordered to be executed at the CNC machine prototype. This prototype of CNC machine is intended to achieve maximum accuracy during the execution of the program.

Upon reaching the completion of CNC machine, logic programming is a function of time and steps which is enabled from the computer via Mach3 software tool.

The Lazy CAM software is used for G-code, which enabled to convert the trajectory of the work pieces from analogue into digital way. Machine-testing is enabled by certain tasks that are correctly dimensioned, then create digital program based on the dimensions of the item, in which case the complicated mechanical details have been taken.

Thus, to achieve the programming phase of task, the machine should possess in advance all the mechanical and electrical elements ready to execute the program. In addition, how the steps have been met on creating and programming the machine movements have been described.

\section{Methods and research techniques}

After completion of the design, the production of mechanical components of the CNC machine has been done. In Figure 1 is presented the 3D SOLIDWORKS assembling model, where all designed elements are produces afterwards. After completion of elements for $\mathrm{x}, \mathrm{y}$ and $\mathrm{z}$ axes, the 3D model has been obtained, as is presented in Figure 2. The model has shown the manner and format how to produce the prototype machine.

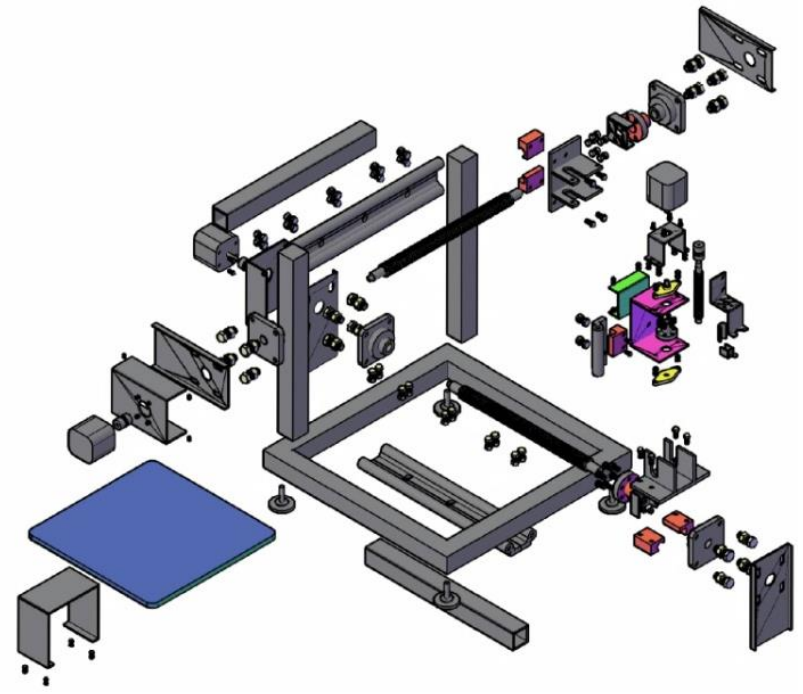

Fig. 1. The CNC machine modelling with $\mathrm{x}, \mathrm{y}$ and $\mathrm{z}$ axes.

\section{Fabrication of mechanical parts}

Here is described the implementation of mechanical parts, based on the graphic design of the CNC machine. In addition, there are shown the pictures of the elements prepared and completed by drawings, defined in Section III of the graphical model.

$\mathrm{X}$ axis is completed by connecting all the needed elements and is tested properly. The axis is formed by:

1. The holder of the metal profile 40x40x2 (mm);

2. Slider and aluminium profiles;

3. Axes with trapeze fillets;

4. Bearing Lodge;

5. Link elements.

Also the $\mathrm{y}$ axis is realized similar to the $\mathrm{x}$ axis, but the difference between the $\mathrm{x}$ and $\mathrm{y}$ axes are that $\mathrm{x}$ axis is linked to $\mathrm{z}$ axis and the $\mathrm{y}$ axis and is connected to the working table.

It is implemented identically as the shape of the $\mathrm{z}$ axis. The latter axis is with the help of a fixed holder of $\mathrm{x}$ axis. The element to the $\mathrm{z}$ axis is formed to the fixed screw lever. $\mathrm{Z}$ axis in a positive/negative direction moves with the rotation of $\mathrm{x}$ axis by the step motor, while the positive/negative displacement of $\mathrm{z}$ axis moves by step motor. These movements enable the displacement of the reference point of a pencil tip. 


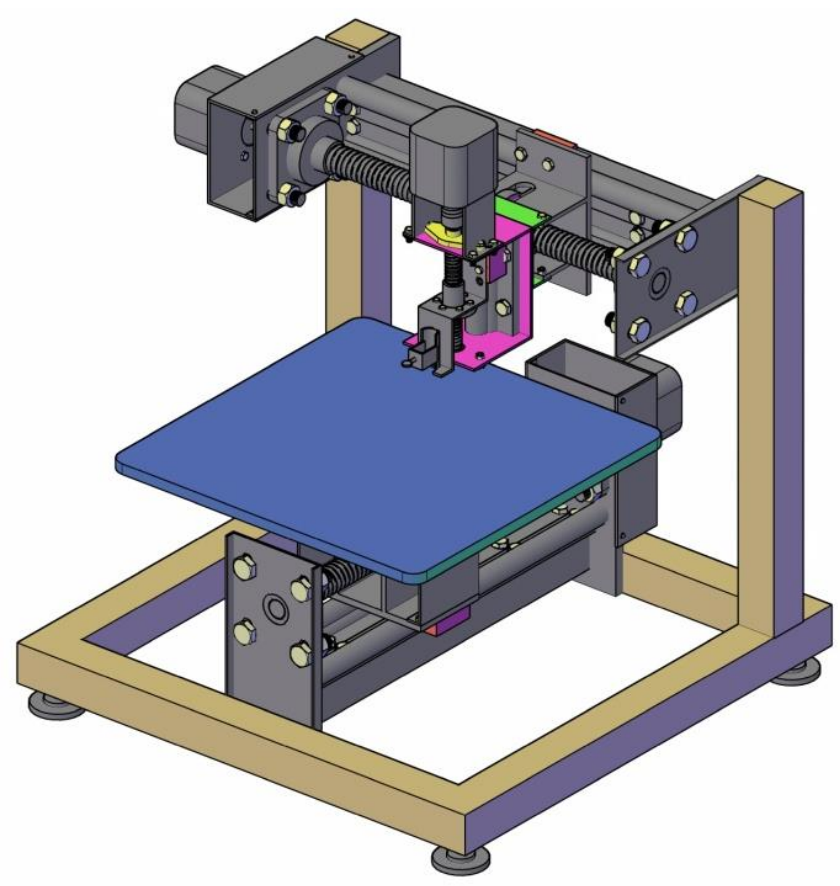

Fig. 2. CNC machine - front side.

In Figure 3 the CNC machine moves in three directions by axes of $\mathrm{x}, \mathrm{y}$ and $\mathrm{z}$ coordinates. Its task is to draw on the working table, so that the movement of the $\mathrm{x}$ axis moves the $\mathrm{z}$ axis, and enables the drawing direction in $\mathrm{x}$ axis, while the movement of the y axis is determined to move the table and contact the tip of the pencil.

If it is requested to form a circle on the working table, then $\mathrm{z}$ axis moves positively with the numerical value assigned by the program, which values change until contacting the tip of the pen with the working table. Then, the values provided by the program by coordinating the movement of $\mathrm{x}$ and $\mathrm{y}$ axes. So forth; begin the movement of the $\mathrm{x}$ axis which carries the $\mathrm{z}$ axis, and the movement of the table from the $\mathrm{y}$ axis. For the circle formation, the function of two movements of $\mathrm{x}$ and $y$ at the same time are needed, but with difference time of the motor step where the circle drawing is enabled.

Calculation and configuration of movements $\mathrm{x}, \mathrm{z}$ and $\mathrm{y}$ axis is given with expression as above:

step per rev $=(M * S) / P$

Where is: $\mathrm{M}$ - motor steps, $\mathrm{S}$ - micro stepping and $\mathrm{P}$ - pitch for lead unscrew nuts.

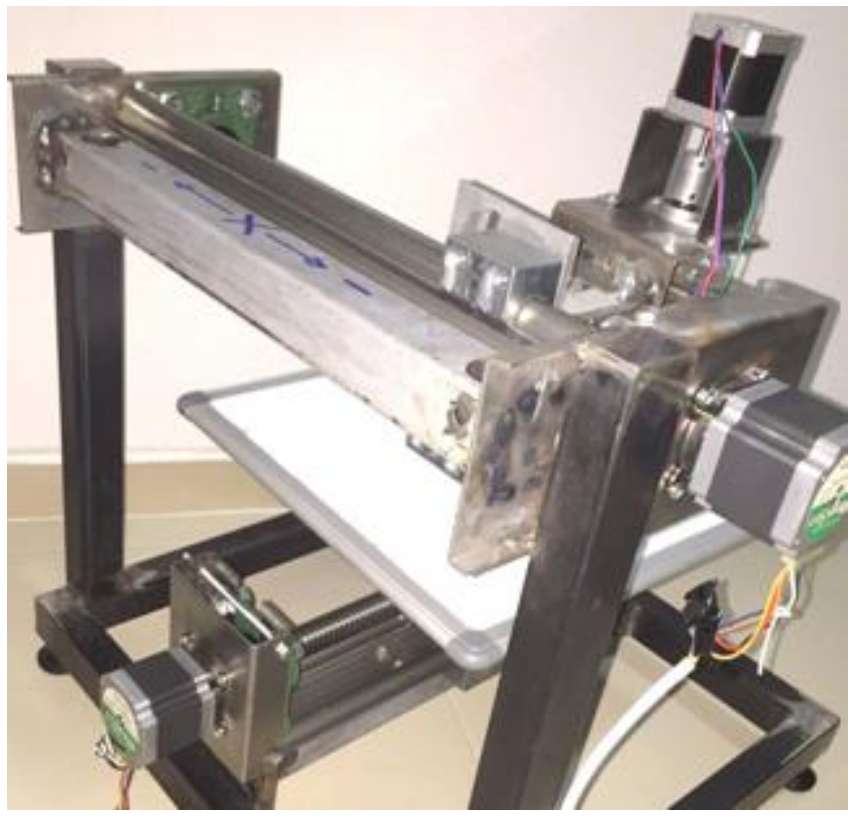

Fig. 3. The $\mathrm{X}, \mathrm{Y}$ and $\mathrm{Z}$ axes of $\mathrm{CNC}$ machine. 


\section{Electrical devices, installation and programming}

In Figure 4 the cabling between motors and TB6560-4V3 controller board is provided. This enabled the transfer of the signals from the computer to the step motors. This signal is determined by the needs of the actions that are required; based on the drawing with pencil has been implemented. Thus, the controller board enables conversion of electrical signals into movements of the CNC machine.

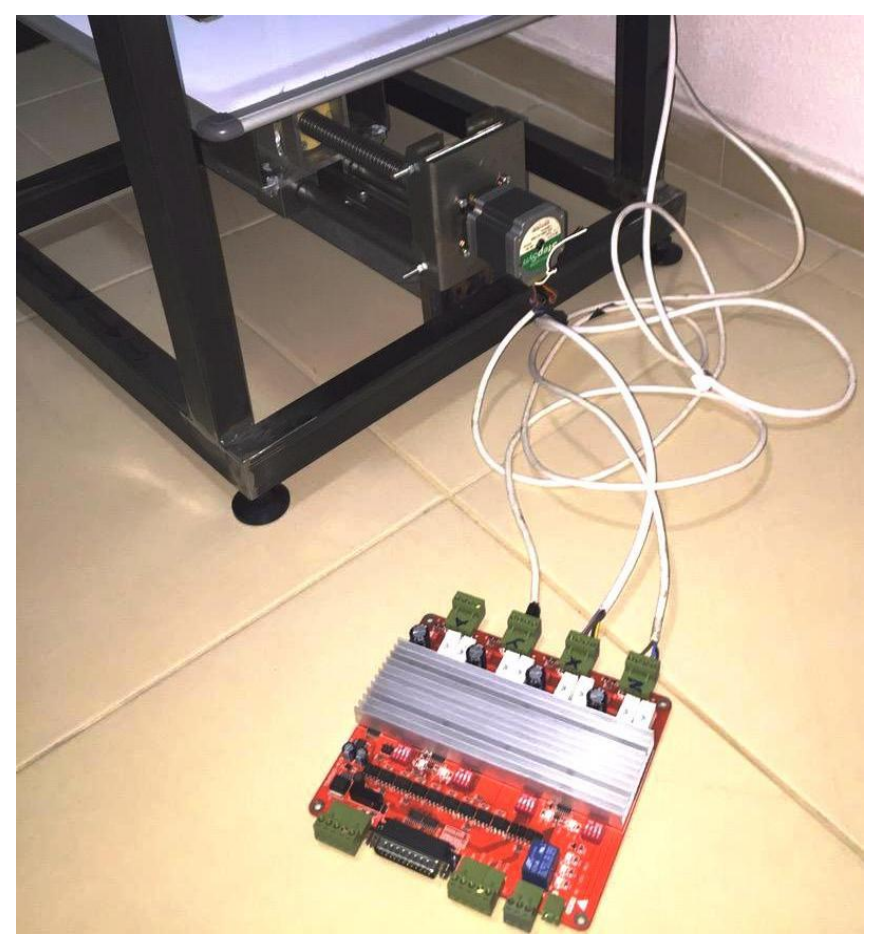

Fig. 4. Plugging the step motors on the TB6560-4V3 control board.

With controlled movements the intention was to draw mechanical drawings with precise dimensions. The Mach3 software tool has been used for putting into operation the CNC machine and its programming. The numerical values of the commands, G-codes etc., by usage of Mach3 software tool, have been programmed. G-codes that enable the conversion of lines into numerical values for the coordinates of the $\mathrm{x}, \mathrm{y}$ and $\mathrm{z}$ axes have been introduced. The CAM software make possibilities to optimize the tool path trajectory and choice the best start point of the CNC Machine tools [15].

A pencil that draws on desktop and performs simulation of a camera head cutter or a cutting tool for metal cutting metal has been taken as an example. The research has been focused on accuracy, speed, quality of work of a prototype machine that is managed to be accomplished.

\section{Obtained results}

The main task of this research work has been the realization of mechanisms for the design and production of mechanical parts of a CNC machine with the electrical items + software. This machine performs controlled movements with the help of the computer and Mach3software tool.

The outcome has been achieved by controlling the movement of the $\mathrm{z}$ axis. The important task was the coordination and functioning of the mechanical parts, including axles, bearings and of all the elements necessary for connecting the metal skeleton.

The result of the research was the selection of electrical control board which converts data from the computer commands to step motors which are linked to the $\mathrm{x}, \mathrm{y}$ and axis of axes.

In Figure 5 is shown a drawing of the work piece-size.

The Mach3 program then is compiled for the mentioned drawing by using G-codes, Figure 6.

The same code, then in CNC machine has been executed, as is shown in Figure 7.

During the study of this prototype machine there are displayed many problems that we overcame and solved in the best engineering methods [14]. From this study one can conclude that the essence of automation mechanisms was to reduce vibration. Also, programming has particular importance; therefore it is done by using the software tools Mach3. Mach3 and CAM software enable programming and simulation of more complex work pieces. Programming enables conversion of numeric codes, which numerical value compel the electromotive to work with steps in function of time. 


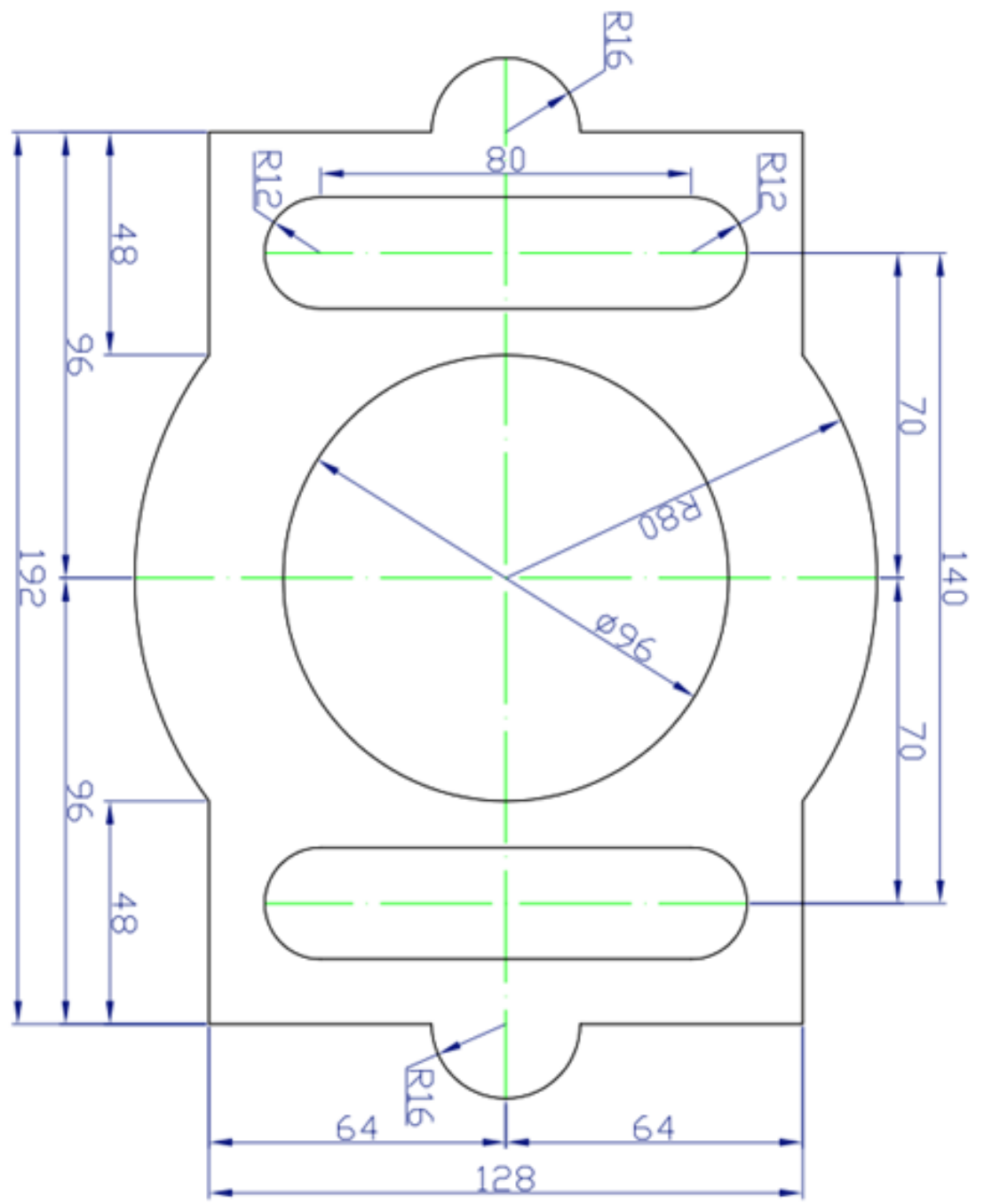

Fig. 5. Work piece drawing.

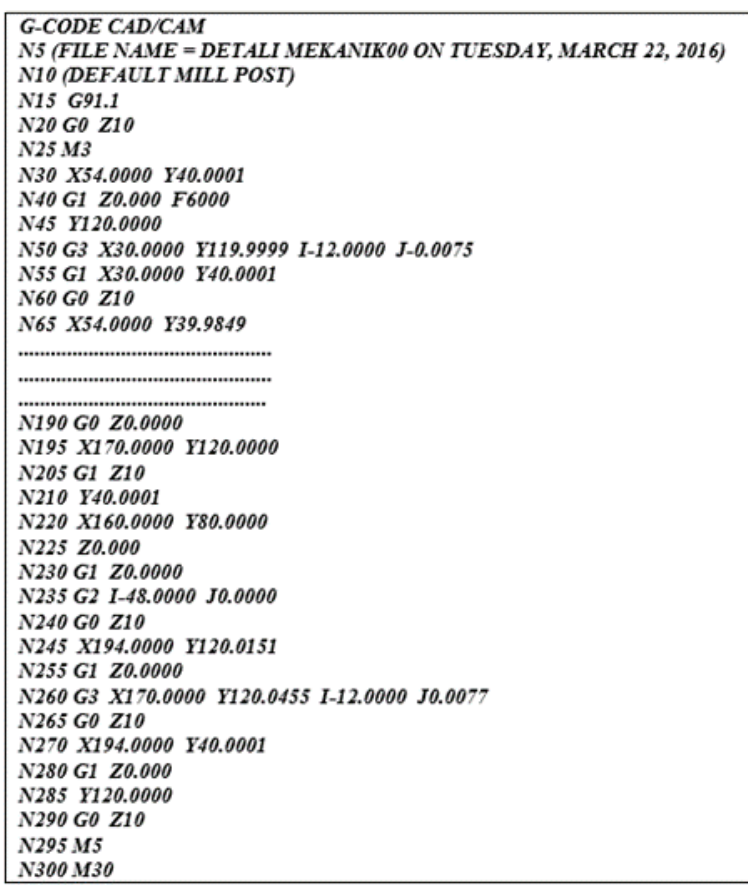

Fig. 6. Listing of the Lazy CAM Mach G-Code. 


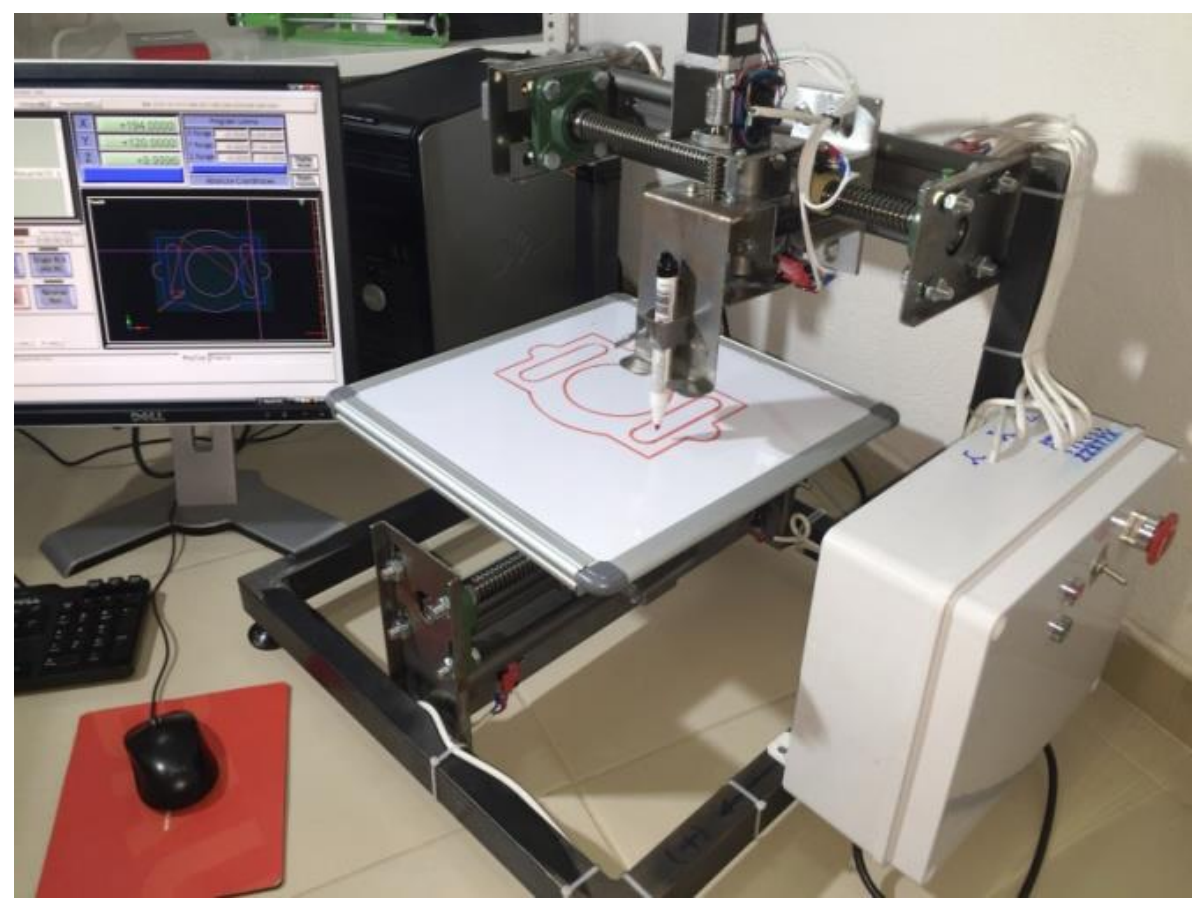

Fig. 7. Realization of the task in CNC machine.

\section{Conclusions}

Relying on the development of mechanical and electrical technology in recent years, now we have increased research interest of automation of the industrial machines. Nowadays it is focused on the manufacturing of a prototype machine which is capable of providing the expected results.

In particular herein is designed and constructed the machine tool with computer numerical control. Manufacturing of the prototype machine has to deal with the mechanical, electrical and software, such as at:

- Mechanical parts: the holders, axles, bearings and other supporting machine elements and connectors.

- Electrical components: Electro motors, controller board, cables and buttons (emergency, limiting and activator).

- Software: In our case we have applied the software Mach3 to machine control.

The study is based on the production of CNC machine that can move in three directions $\mathrm{x}, \mathrm{y}$ and $\mathrm{z}$ axes. $\mathrm{Z}$ axis is used for the main task, as there was located a pen for drawing. One can replace the pen with any other device which makes metal cutting or drilling, since the machine enables the controlled movement along $\mathrm{z}$ axis, where we can set any cutting tool.

The goal of the study has been achieved, i.e., the production and programming of CNC mechanical device is accomplished. Regarding the accuracy of the drawing the trajectory, it can be achieved with the usage of certain commands in Mach3 where software automatically calibrates the ratio between motor and spindle moving step.

Future plans would be implementation of tool selection method and camera for metal processing, instead of using the pen for drawing, and calculation of all the forces caused during the metal processing. Also, the usage of Matlab software should be considered for design, optimization of machining parameters, and cutting forces.

\section{References}

[1] Spath, D., Rosum, J., A. Haberkern, A., (1995). Kinematics Friction a I Characteristics and Wear Reduction by PVD Coating on Ball Screw Drives, Annals of the CIRP - Manufacturing Technology, Vol. 44, Issue 1, pp. 349-352, doi.org/10.1016/S0007-8506(07)62340-3

[2] Weule H., and Frank, T., (1999). Advantages and Characteristics of a Dynamic Feeds Axis with Ball Screw Drive and Driven Nut, Annals of the CIRP Vol. 48, Issue 1, pp. 303-306., doi.org/10.1016/S0007-8506(07)63189-8

[3] Zhou, Y., Peng, F.Y., and Cao, X.H., (2011). Parameter sensitivity analysis of axial vibration for lead-screw feed drives with time-varying framework, Mechanics, Vol. 17, No. 5, pp. 523-528., ISSN 1392-1207

[4] Prévost, D., and Lavernhe, S., Dumur, D., (2011). Feed drive modelling for the simulation of tool path tracking in multi-axis High Speed Machining, International Journal of Mechatronics and Manufacturing System, Vol. 4, pp. 266-284, 10.1504/IJMMS.2011.041472

[5] Altintas, Y., Brecher, C., Weck, M., Witt S., (2005). Virtual Machine Tool, CIRP Annals - Manufacturing, Technology, Vol. 54, Issue 2, pp. 115-138 
[6] Lavernhe, S., Tournier, C., Lartigue, C, (2008). Kinematical performance prediction in multi-axis machining for process planning optimization', International Journal of Advanced Manufacturing Technology, Vol. 37, No. 5, pp. 534-544, DOI 10.1007/S00170-007-1001-4

[7] Y. Altintas, K. Erkorkmaz, W.-H. Zhu, (2000). Sliding Mode Controller Design for High Speed Feed Drives. Annals of the CIRP Vol. 49, Issue 1, pp. 265-270

[8] Min-Seok Kim a, Sung-Chong Chung, (2006). Integrated design methodology of ball-screw driven servomechanisms with discrete controllers. Part I: Modelling and performance analysis, Mechatronics 16, Elsevier, pp. 491-502, DOI:10.1016/J.Mechatronics.2006.01.008.

[9] H. B. Lacerda, Dr. Eng., E. M. Belo, (1999). Application of a PID+Fuzzy Controller on the Motion Control System in Machine Tools, Ph.D Thesis, J. Braz. Soc. Mech. Sci. Vol. 21, No. 3, Rio de Janeiro.

[10] Jin-Sung Kim, Jin-Hwan Kim, Ji-Mo Park, Sung-Man Park, Won-Yong Choe and Hoon Heo, (2008). Auto Tuning PID Controller based on Improved Genetic Algorithm for Reverse Osmosis Plant, World Academy of Science, Engineering and Technology 47., pp. 384-389.

[11] Isayyad Naimuddin, B. Warkad, Dr. G. M. Dhole, Mohammad Nasiruddin (2009). Enhancing The Operational Availability Of CNC Machine Using Fuzzy Logic Controller, Journal Of Theoretical And Applied Information Technology, pp. 145-154.

[12] Cus F., Zuperl U., Balič J., (2011). Combined feedforward and feedback control of end milling system, Journal of Achievements in Materials and Manufacturing Engineering. Vol. 45, ISSUE 1, pp. 79-88.

[13] Gayathri Monicka Dr. N.O.Guna Sekhar K. Ramash Kumar, (2011). Performance Evaluation of Membership Functions on Fuzzy Logic Controlled AC Voltage Controller for Speed Control of Induction Motor Drive, International Journal of Computer Applications, Vol. 13, No.5, pp. 8-12. ISSN 0975-8887

[14] Asllani, T. (2016). CNC Mechanical Device Design and Programming with Mach3, Master Thesis, Department of Construction and Design, University of Prishtina, Prishtina, Kosovo.

[15] Gjelaj, A., Balič, J. and Fičko, M., (2013). Intelligent optimal tool selections for CNC programming of machine tools. Transactions of FAMENA, Vol. 37, No. 3, pp.31-40, ISSN 1333-1124. 